\title{
ARTIGO
}

do https://doi.org/10.22481/praxisedu.v15i34.5461

\section{COMPETÊNCIAS MATEMÁTICAS NA BNCC: IMPLICAÇÕES CURRICULARES}

\author{
MATHEMATICAL SKILLS AT BNCC: CURRICULAR IMPLICATIONS
}

COMPETENCIAS MATEMÁTICAS EN LA BNCC: IMPLICACIONES CURRICULARES

\author{
Daiane Kipper \\ Universidade de Santa Cruz do Sul - Brasil \\ Cláudio José de Oliveira \\ Universidade de Santa Cruz do Sul - Brasil
}

\author{
Lívia Bittencourt Gomes \\ Universidade Regional do Noroeste do Estado do Rio Grande do Sul - Brasil
}

\begin{abstract}
Resumo: O presente trabalho tem por objetivo analisar as Competências específicas de Matemática para o Ensino Fundamental da Base Nacional Comum Curricular (BNCC). Para isso, selecionamos como material de pesquisa excertos do referido documento. Como referencial teórico-metodológico assumimos o pensamento de Michel Foucault e Zigmunt Bauman e suas interlocuções com o campo da Educação Matemática. Com base nas análises do material, compreendemos que a Matemática, enquanto componente curricular, é apresentada como um conhecimento a ser aplicado e utilizado pelo aluno nessa autorresponsabilização e flexibilização, pois cabe a ele encontrar formas de utilizá-la. A aplicação e a solução de problemas são apontadas como competências a serem desenvolvidas na Educação Básica e efetivadas pelo currículo escolar. As discussões em torno das competências elucidadas pela BNCC apresentam que o referido documento está a serviço da nova configuração econômica mundial. $\mathrm{O}$ documento vem a instituir uma forma de matematizar e agir, como sendo importante para os processos de aprendizagem.
\end{abstract}

Palavras-chave: Base nacional comum curricular. Currículo escolar. Educação matemática.

Abstract: The present work has the objective of analyzing the specific Mathematical Competences for the Basic Teaching of the National Curricular Common Base (BNCC). To do this, we selected excerpts from this document as research material. As a theoretical-methodological reference we assume the thinking of Michel Foucault and Zigmunt Bauman and their interlocutions with the field of Mathematical Education. Based on the material analysis, we understand that Mathematics, as a curricular component, is presented as a knowledge to be applied and used by the student in this selfresponsibility and flexibility, because it is up to them to find ways to use it. The application and the solution of problems are pointed out as competences to be developed in Basic Education and made effective by the school curriculum. The discussions about the competences elucidated by BNCC show 
that this document serves the new global economic configuration. The document establishes a way of mathematizing and acting, as being important for the learning processes.

Keywords: Mathematical education. National common curricular base. School curriculum.

Resumen: El presente trabajo tiene por objetivo analizar las Competencias específicas de Matemáticas para la Enseñanza Primaria de la Base Nacional Común Curricular (BNCC). Para ello, seleccionamos como material de investigación fragmentos del referido documento. Como referencial teórico-metodológico, asumimos el pensamiento de Michel Foucault y Zigmunt Bauman y sus interlocuciones con el campo de la Educación Matemática. Con base en los análisis del material, comprendemos que las Matemáticas, como componente curricular, son presentadas como un conocimiento a ser aplicado y utilizado por el alumno en esa autoresponsabilización y flexibilización, pues le comprende encontrar formas de utilizarlas. La aplicación y la solución de problemas son apuntadas como competencias a ser desarrolladas en la Educación Básica y realizadas por el currículo escolar. Las discusiones acerca de las competencias dilucidadas por la BNCC presentan que el referido documento está al servicio de la nueva configuración económica mundial. El documento viene a instituir una forma de matematizar y actuar, como importante para los procesos de aprendizaje.

Palabras clave: Base nacional común curricular. Currículum escolar. Educación matemática.

\section{Uma introdução à BNCC}

No Brasil, a Educação vem sendo organizada por leis e medidas provisórias. Para ilustrar isso, apresentamos, neste texto introdutório, uma cronologia dos documentos legais que pautaram e ainda pautam os modos de pensar a Educação Básica no país com o objetivo de contextualizar as condições de possibilidade para a elaboração da Base Nacional Comum Curricular (BNCC).

Tomamos como partida a Constituição Federal que foi promulgada em 1988, na qual o Capítulo III intitulado Da Educação, da Cultura e do Desporto estabelece no artigo 210 que: "Serão fixados conteúdos mínimos para o ensino fundamental, de maneira a assegurar formação básica comum e respeito aos valores culturais e artísticos, nacionais e regionais" (BRASIL, 1988). Posterior à Constituição Federal, no ano de 1996, é aprovada a Lei de Diretrizes e Bases da Educação Nacional, a qual estabelece no Artigo $1^{\circ}$ do Título 1 que: “A educação abrange os processos formativos que se desenvolvem na vida familiar, na convivência humana, no trabalho, nas instituições de ensino e pesquisa, nos movimentos sociais e organizações da sociedade civil e nas manifestações culturais” (BRASIL, 1996).

De 1997 a 2000, os Parâmetros Curriculares Nacionais (PCNs), a partir das Diretrizes Nacionais Curriculares (DCNs), foram apresentados aos educadores. Nesses documentos, foi dado destaque às características de cada componente curricular. Os PCNs foram organizados 
em partes: do $1^{\circ}$ ao $5^{\circ}$ ano em 1997; do $6^{\circ}$ ao $9^{\circ}$ ano em 1998; e do Ensino Médio em 2000. No ano 2000, acontece a Conferência Nacional de Educação (CONAE), com a participação da sociedade civil, de agentes públicos, entidades de classe, estudantes, profissionais da educação e responsáveis de estudantes, que resultou na elaboração de documentos que são referência para a construção de políticas de Estado e para a educação nacional e articulam-se com os documentos citados anteriormente.

De 2010 a 2012, foram apresentadas as Diretrizes Curriculares Nacionais Gerais para a Educação Básica que estabelecem, de acordo com o Artigo $1^{\circ}$, o direito da pessoa "ao seu pleno desenvolvimento, à preparação para o exercício da cidadania e à qualificação para o trabalho, na vivência e convivência em ambiente educativo" (BRASIL, 2010, p. 824). Elas têm como fundamento a responsabilização do Estado brasileiro, da família e da sociedade em garantir a democratização do acesso, a inclusão, a permanência e a conclusão com sucesso das crianças, dos jovens e adultos na instituição educacional, assim como a aprendizagem para a continuidade dos estudos e a extensão da obrigatoriedade e da gratuidade da Educação Básica (BRASIL, 2010).

No ano de 2014, a Lei 13.005 de 2014 instituiu o Plano Nacional de Educação (PNE) com vigência de 10 anos, em que foram apresentadas 20 metas que objetivam melhorar a Educação Básica no Brasil (BRASIL, 2014). No ano de 2015, foi iniciada a elaboração da Base Nacional Comum Curricular (BNCC). Para isso, foi realizado o I Seminário Interinstitucional para a elaboração da Base, reunindo assessores e especialistas. Em outubro do mesmo ano, iniciou-se a consulta pública para a construção da primeira versão da BNCC, tendo contribuições da sociedade civil, de organizações e entidades científicas. Em 2016, a primeira versão do documento é finalizada. E, em junho do mesmo ano, foram realizados debates sobre a segunda versão da BNCC. Em agosto de 2016, começou a ser redigida a terceira versão, que tem como base a segunda. Em 2017, o Ministério da Educação (MEC) entregou a versão final BNCC ao Conselho Nacional de Educação (CNE) que foi aprovada em dezembro de 2017.

No presente estudo, trataremos especialmente da versão final aprovada da BNCC como material empírico. Para isso, objetivamos analisar as implicações curriculares das Competências específicas de Matemática para o Ensino Fundamental da BNCC, apresentando como justificativa que o referido documento é "de caráter normativo que define o conjunto orgânico e progressivo de aprendizagens essenciais que todos os alunos devem desenvolver ao longo das etapas e modalidades da Educação Básica” (BRASIL, 2017, p. 7). Nesse aspecto, se faz relevante estudar o referido documento no que remete às questões do 
campo da Educação Matemática, tomando como base a preocupação da Associação Nacional de Pós-Graduação e Pesquisa em Educação (ANPEd) e da Associação Brasileira de Currículo $(\mathrm{ABdC})$ em relação à unificação dos conteúdos via apostilização do ensino, tratando de forma igual a diferença como está sendo proposto na BNCC. As referidas associações divulgaram uma nota, na página da própria ANPEd, lamentando a aprovação da BNCC:

Nossa posição de que a BNCC, em seus princípios e metodologia de elaboração sem consulta à comunidade educacional afronta a condição de democracia para gestão e currículos além de abduzir a pluralidade dos conhecimentos escolares e desqualificar o trabalho docente é pública e expressa nossa preocupação com o aumento da desigualdade e da exclusão social (ASSOCIAÇÃO NACIONAL DE PÓS-GRADUAÇÃO E PESQUISA EM EDUCAÇÃO, 2017).

Nessa perspectiva, apresentamos como empiria da pesquisa, as competências específicas de matemática ${ }^{1}$ propostas pela BNCC para serem desenvolvidas nos Anos Iniciais e nos Anos Finais do Ensino Fundamental, que estão organizadas no quadro a seguir.

Quadro 1 - Competências específicas de matemática para o ensino fundamental

\section{COMPETÊNCIAS ESPECÍFICAS DE MATEMÁTICA PARA O ENSINO FUNDAMENTAL}

1. Identificar os conhecimentos matemáticos como meios para compreender e atuar no mundo, reconhecendo também que a Matemática, independentemente de suas aplicações práticas, favorece o desenvolvimento do raciocínio lógico, do espírito de investigação e da capacidade de produzir argumentos convincentes.

2. Estabelecer relações entre conceitos e procedimentos dos diferentes campos da Matemática (Aritmética, Álgebra, Geometria, Estatística e Probabilidade) e de outras áreas do conhecimento e comunicá-las por meio de representações adequadas.

3. Fazer observações sistemáticas de aspectos quantitativos e qualitativos presentes nas práticas sociais e culturais, de modo a investigar, organizar, representar e comunicar informações relevantes, para interpretá-las e avaliá-las crítica e eticamente, produzindo argumentos convincentes.

4. Enfrentar situações-problema em múltiplos contextos, incluindo-se situações imaginadas, não diretamente relacionadas com o aspecto prático-utilitário, expressar suas respostas e

\footnotetext{
1 De acordo com a BNCC: "Cada área de conhecimento estabelece competências específicas de área, cujo desenvolvimento deve ser promovido ao longo dos nove anos. Essas competências explicitam como as dez competências gerais se expressam nessas áreas" (BRASIL, 2017, p. 26).
} 
sintetizar conclusões, utilizando diferentes registros e linguagens: gráficos, tabelas, esquemas, além de texto escrito na língua materna.

5. Utilizar processos e ferramentas matemáticas, inclusive tecnologias digitais disponíveis, para modelar e resolver problemas cotidianos, sociais e de outras áreas de conhecimento, validando estratégias e resultados.

6. Agir individual ou cooperativamente com autonomia, responsabilidade e flexibilidade, no desenvolvimento e/ou discussão de projetos, que abordem, sobretudo, questões de urgência social, com base em princípios éticos, democráticos, sustentáveis e solidários, valorizando a diversidade de opiniões de indivíduos e de grupos sociais, sem preconceitos de qualquer natureza.

7. Interagir com seus pares de forma cooperativa, trabalhando coletivamente no planejamento e desenvolvimento de pesquisas para responder a questionamentos e na busca de soluções para problemas, de modo a identificar aspectos consensuais ou não na discussão de uma determinada questão, respeitando o modo de pensar dos colegas e aprendendo com eles.

8. Sentir-se seguro da própria capacidade de construir e aplicar conhecimentos matemáticos, desenvolvendo a autoestima e a perseverança na busca de soluções.

9. Reconhecer que a Matemática é uma ciência humana, fruto das necessidades e preocupações de diferentes culturas, em diferentes momentos históricos, e é uma ciência viva, que contribui para solucionar problemas científicos e tecnológicos e para alicerçar descobertas e construções, inclusive com impactos no mundo do trabalho (BRASIL, 2017, p. 223).

Fonte: Quadro elaborado pelos autores com base nas Competências específicas de Matemática para o Ensino Fundamental da BNCC.

De acordo com o referido documento as competências específicas do componente curricular

[...] possibilitam a articulação horizontal entre as áreas, perpassando todos os componentes curriculares, e também a articulação vertical, ou seja, a progressão entre o Ensino Fundamental - Anos Iniciais e o Ensino Fundamental - Anos Finais e a continuidade das experiências dos alunos, considerando suas especificidades (BRASIL, 2017, p. 26).

Essas competências também devem estar articuladas às dez competências gerais da BNCC e seu desenvolvimento deve ser garantido pelo componente curricular de Matemática. 
Com base nas análises realizadas dessas competências, organizamos o presente estudo em quatro seções: a primeira seção intitulada Uma introdução à BNCC, em que apresentamos os documentos legais que pautam a Educação no Brasil e se articulam com a BNCC, bem como o objetivo e a empiria da pesquisa; a segunda seção nomeada como Velhos temas, novos problemas: competências matemáticas na BNCC, em que apresentamos as análises das competências específicas para o Ensino Fundamental na perspectiva dos estudos de Michel Foucault e Zigmunt Bauman; na terceira seção destacamos algumas questões para pensar a posição hegemônica da Matemática no currículo escolar, intitulando-a como A regulação do conhecimento matemático no currículo escolar, para isso nos apoiamos em autores do campo da Educação Matemática em interlocução com as noções do currículo escolar; na quarta seção, nomeada como Questões para finalizar, apresentamos as considerações finais; e, por fim, citamos as referências que embasam a pesquisa.

\section{Velhos temas, novos problemas: competências matemáticas na BNCC}

Competência, de acordo com o Dicionário Houaiss da Língua Portuguesa 2009, significa a "soma de conhecimentos ou de habilidades" (HOUAISS; VILLAR, 2009) e, para a BNCC, competência é entendida como o conhecimento mobilizado, operado e aplicado em situação (BRASIL, 2017). Na BNCC:

[...] a noção de competência é utilizada no sentido da mobilização e aplicação dos conhecimentos escolares, entendidos de forma ampla (conceitos, procedimentos, valores e atitudes). Assim, ser competente significa ser capaz de, ao se defrontar com um problema, ativar e utilizar conhecimento construído (BRASIL, 2017, p. 16).

O documento também argumenta que a elaboração de currículos referenciados em competências tem sido uma tendência também em outros países desde as décadas finais do século XX e do início do século XXI, sendo esse o enfoque que é dado nas avaliações internacionais, como o Programa Internacional de Avaliação de Alunos (Pisa, Sigla em inglês) (ORGANIZAÇÃO DE COOPERAÇÃO E DESENVOLVIMENTO ECONÔMICO, 2016). De acordo com a BNCC, a LDB já fazia menção de forma explícita a competências, as quais deveriam nortear os currículos nas instituições de ensino. Entretanto, elas reaparecem, de forma mais explícita e detalhada, nos PCNs, onde são apontadas as competências e habilidades a serem adquiridas pelos alunos em todas as áreas do conhecimento. 
Com base nesse enfoque, a explicitação de competências apresenta o que os alunos devem saber e, sobretudo, o que os alunos devem saber fazer, e isso é caracterizado pelo documento como resultado de sua aprendizagem. Ao fazer o escrutínio do documento, olhamos para ele como monumento, segundo Veiga-Neto (2012) os materiais devem ser observados no seu volume e na sua exterioridade, ou seja, como monumentos. Desse modo, estudamos as Competências específicas de Matemática para o Ensino Fundamental e percebemos a ênfase dada a: aplicações práticas; práticas sociais e culturais; comunicar informações; enfrentar situações-problema em múltiplos contextos; linguagem; usar processos e ferramentas matemáticas, inclusive tecnologias digitais; agir individual ou cooperativamente com autonomia, responsabilidade e flexibilidade; trabalho coletivo; busca de soluções para problemas; apreender com os colegas; aplicar conhecimentos matemáticos; e ao mundo do trabalho.

Assim, podemos perceber as subjetividades que se deseja produzir na Educação Básica e que se espera desenvolver como resultado da aprendizagem, uma vez que elas já aparecem em documentos anteriores à BNCC, como nos PCNs, por exemplo. Dessa forma, há condições para que os discursos da BNCC circulem e, ao mesmo tempo, são produzidos e produzem a sociedade, pois apresentam condutas a serem formalizadas no Ensino Fundamental, ou seja, modos de pensar e de se organizar no espaço e tempo que já estão implicados em documentos anteriores e, assim, já circulam nas instituições de ensino. Somer (2007), apoiado em Foucault, apresenta que os discursos são práticas que organizam a realidade. Para o autor, os "discursos estabelecem hierarquias, distinções, articulam o visível e o dizível” (SOMER, 2007, p. 58), ou seja, o foco não está no significado da palavra, mas sim no papel que desempenha nas práticas sociais.

Nessa perspectiva teórica, olhamos para a BNCC como um monumento e analisamos suas escritas como discurso, ou seja, como uma produção social em um determinado tempo e espaço. Sendo que

[...] em toda sociedade a produção do discurso é ao mesmo tempo controlada, selecionada, organizada e redistribuída por certo número de procedimentos que têm por função conjurar seus poderes e perigos, dominar seu acontecimento aleatório, esquivar sua pesada e temível materialidade (FOUCAULT, 1998, p. 8-9).

Assim, compreendemos que "o discurso não é simplesmente aquilo que traduz as lutas ou os sistemas de dominação, mas aquilo por que, pelo que se luta, o poder do qual nos queremos apoderar" (FOUCAUL, 1998, p. 10). 
Assim, o currículo é também uma questão de poder, logo "na medida em que buscam dizer o que currículo deve ser, não podem deixar de estar envolvidas em questão de poder. Privilegiar um tipo de conhecimento é uma operação de poder” (SILVA, 2016, p. 16). Ao entendermos o currículo escolar como o "resultado de uma seleção: de um universo mais amplo de conhecimentos e saberes seleciona-se aquela parte que vai constituir precisamente o currículo" (SILVA, 2016, p. 15), compreendemos que a efetivação da BNCC nas escolas, amparada nas leis que instituem a educação no Brasil desde 1988, produz discursos no que tange o currículo escolar e, consequentemente, produz modos de conceber e compreender o mundo.

Ao olhar para o documento, com essas lentes teóricas, compreendemos que as competências específicas a serem desenvolvidas pela Matemática no Ensino Fundamental produzem modos de conceber o conhecimento matemático bem como modos de pensar e de agir enquanto cidadãos, ou seja, pessoas inseridas na sociedade. Na competência número 4:

Enfrentar situações-problema em múltiplos contextos, incluindo-se situações imaginadas, não diretamente relacionadas com o aspecto prático-utilitário, expressar suas respostas e sintetizar conclusões, utilizando diferentes registros e linguagens: gráficos, tabelas, esquemas, além de texto escrito na língua materna (BRASIL, 2017, p. 223, grifo nosso).

E na competência número 5: "Utilizar processos e ferramentas matemáticas, inclusive tecnologias digitais disponíveis, para modelar e resolver problemas cotidianos, sociais e de outras áreas de conhecimento, validando estratégias e resultados" (BRASIL, 2017, p. 223, grifo nosso) é possível perceber questões relacionadas ao neoliberalismo como competências a serem desenvolvidas na Educação Básica.

O enfoque dado nessas duas competências vai ao encontro do pensamento do sociólogo Zygmunt Bauman. Em uma entrevista realizada pela professora Alba Porcheddu, o sociólogo discute questões sobre a educação e de como a mesma tem se configurado na modernidade líquida. Bauman (2009) explica que no mundo líquido moderno a ideia de assumir um compromisso duradouro é interpretada como uma ameaça. A durabilidade não é mais uma qualidade, pois é necessário eliminar, descartar coisas.

Presume-se que as coisas e as relações são úteis apenas por um "tempo fixo" e são reduzidas a farrapos ou eliminadas uma vez que se tornam inúteis. Portanto é necessário evitar ter bens, sobretudo aqueles duráveis dos quais é difícil de desprender. O consumismo de hoje não visa ao acúmulo de coisas, mas à sua máxima utilização. Por qual motivo, então, "a bagagem de conhecimentos" construída nos bancos da escola, na universidade, deveria 
ser excluída dessa lei universal? Este é o primeiro desafio que a pedagogia deve enfrentar, ou seja, um tipo de conhecimento pronto para a utilização imediata e, sucessivamente, para sua imediata eliminação, como aquele oferecido pelos programas de software (atualizados cada vez mais rapidamente e, portanto, substituídos), que se mostra muito mais atraente do que aquele proposto por uma educação sólida e estruturada. (BAUMAN, 2009, p. 663).

Nessa perspectiva, o conhecimento acumulado nas escolas e universidades vem sendo substituído por um tipo de conhecimento para a utilização imediata e sua posterior eliminação. Com a velocidade do mundo moderno líquido, o conhecimento se torna rapidamente velho, e essa volatilidade exige competências, as quais se tornam vãs com o passar do tempo. Suspeitamos que o pensamento do sociólogo, no que tange à forma como as escolas estão imersas nesse mundo nomeado por ele como líquido, vai ao encontro do que visam as competências explicitadas pela BNCC, as quais se contrapõem "à concepção de conhecimento desinteressado e erudito entendido como fim em si mesmo" (BRASIL, 2017, p. 17) e esboçam a utilização do conhecimento.

A competência de número 5 explana a concepção de um conhecimento utilitário, ou seja, se refere à utilização do conhecimento matemático para a resolução de problemas cotidianos. Bauman (2009) faz uma analogia com o funcionamento dos mísseis para ilustrar que conhecimento, na modernidade líquida, tem se configurado como algo que deve ser descartado quando não há mais utilidade para o mesmo. O sociólogo explica que os mísseis inteligentes, diferentemente dos mísseis balísticos (mísseis com alvo e trajetória previamente definidos), calculam no ar mudando rapidamente de objetivo.

Assim, devem ser inicialmente dotados da capacidade de aprender e de aprender de modo rápido. Isso é obvio. O que é menos evidente, se bem não menos importante dentro de uma rápida capacidade de aprendizagem, é todavia a capacidade de esquecer instantaneamente o que se aprendeu antes. (BAUMAN, 2009, p. 672).

A BNCC não faz menção ao descarte do que se aprende, entretanto nas competências analisadas é dada ênfase à utilização de tecnologias digitais para modelar e resolver problemas dos diferentes contextos, logo o aluno deve ser capaz de lidar com situações novas e de forma rápida e sintética.

Do mesmo modo, as respostas devem ser registradas de forma sintética em sua língua materna e de forma escrita. A forma escrita exclui outras formas de linguagem, uma vez que podem ser também visuais e orais, por exemplo. Na dissertação Práticas matemáticas visuais 
produzidas por alunos surdos: entre números, letras e sinais, essas questões em torno da ênfase que é dada à escrita, no currículo escolar, são discutidas pela autora. No referido estudo, é apresentado que na Matemática há uma valorização da escrita, que deve seguir rigor e padrões que são estimados por ela e, assim, há uma desvalorização da matemática oral presente em outras culturas. De forma análoga, a matemática visual que é praticada por alunos surdos não é valorizada enquanto forma de praticar matemática (KIPPER, 2015). A forma visual do conhecimento é citada somente nas Competências gerais da BNCC, onde é explicitada a utilização dos conhecimentos das:

[...] linguagens verbal (oral e escrita) e/ou verbo-visual (como Libras), corporal, multimodal, artística, matemática, científica, tecnológica e digital para expressar-se e partilhar informações, experiências, ideias e sentimentos em diferentes contextos e, com eles, produzir sentidos que levem ao entendimento mútuo. (BRASIL, 2017, p. 18, grifo nosso).

A competência número 4, específica de Matemática para o Ensino Fundamental, faz menção somente ao registro escrito, logo as demais formas de expressar o conhecimento matemático não são reconhecidas no referido documento. Assim, o registro escrito do conhecimento matemático fica restrito pela representação por gráficos, tabelas e esquemas. Nesse âmbito, não há espaço para a forma de matematizar de outras culturas. Gelsa Knijnik já apontava para essa problemática quando foi solicitada a emitir um parecer sobre a versão preliminar dos PCNs (Documento Introdutório e o específico da área de Matemática). Primeiramente, ela criticou o fato da comunidade diretamente envolvida com a Educação não ter participado das decisões do que deveria e poderia ser feito para alterar os baixos índices na Educação. Também faz uma crítica à adjetivação dada aos PCNs, pelo fato de apresentar um caráter nacional em um país marcado pela diversidade. Knijnik (1996) faz os seguintes questionamentos em relação ao conjunto de conhecimentos elaborados e reconhecidos como necessários para a cidadania, aos quais todos devem ter acesso e que são expostos no referido documento:

[...] tais conhecimentos foram elaborados e reconhecidos por que grupos desta sociedade tão fortemente marcada pela desigualdade? Que vozes têm sido silenciadas neste processo seletivo que determina quais saberes são legítimos e dignos de serem chamados de conhecimentos elaborados. (KNIJNIK, 1996, p. 254).

Knijnik (1996) já sinalizava, em seu parecer sobre os PCNs, sua preocupação em relação à elaboração de uma proposta nacional para os currículos escolares do país, apontando 
para os conhecimentos não reconhecidos pela proposta. A autora também explica que a cultura local é "valorizada" somente quando os saberes locais são tidos como ponto de partida para a aprendizagem. A problemática apresentada nos PCNs se reatualiza com a BNCC, como já dito no título desta seção - Velhos temas, novos problemas: competências matemáticas na $B N C C$ - inspirado no texto Velhos temas, novos problemas - a arte de perguntar em tempos pós-modernos, da Marisa Vorraber Costa. Essa autora apresenta questões para pensarmos sobre a pesquisa em Educação, sobre a importância de organizar as questões de pesquisa não no sentido de procurar o que fazer, mas sim instigando-nos a "armar uma perspectiva" para ver, para lidar com o tema.

A pesquisa em Educação deve mobilizar quem pesquisa, ou seja, deve mexer em nossas certezas. Assim, olhamos para o documento - BNCC - com estranhamento, questionando e problematizando o que está posto. "Perguntas que nos conduzem desafiadoramente estão intrinsecamente vinculadas a formas particulares de ver, compreender e atribuir sentido ao mundo" (COSTA, 2005, p. 201).

Seguindo nossas problematizações em torno da BNCC, a competência número 6 apesenta:

Agir individual ou cooperativamente com autonomia, responsabilidade $e$ flexibilidade, no desenvolvimento elou discussão de projetos, que abordem, sobretudo, questões de urgência social, com base em princípios éticos, democráticos, sustentáveis e solidários, valorizando a diversidade de opiniões de indivíduos e de grupos sociais, sem preconceitos de qualquer natureza (BRASIL, 2017, p. 223, grifo nosso).

Essa competência pode ser pensada a partir do texto Governamentalidades, neoliberalismo e educação, do autor Veiga-Neto (2011), em que são problematizadas possíveis articulações entre a governamentalidade ${ }^{2}$, o neoliberalismo e a educação. $O$ liberalismo é apresentado como uma forma de vida inventada no século XVIII, deslocando-se para o neoliberalismo a partir do século XX. No liberalismo, a liberdade do mercado era entendida como algo natural, já no neoliberalismo a liberdade deve ser produzida como forma de competição. Há uma mudança da ênfase, em que o foco se desloca da produção para a competição. "Na modernidade sólida, a fábrica disciplinar, com sua rotina monótona e seu futuro, bloqueavam o acontecimento. Na modernidade líquida - ou, se quisermos, na

2 Governamentalidade é compreendida pelo mesmo como "um conjunto constituído pelas instituições, procedimentos, análises e reflexões, cálculos e táticas que permitem exercer essa forma bem específica, bem como forma mais importante de saber, a economia política, como instrumento técnico essencial, os dispositivos de segurança" (FOUCAULT, 2003, p. 303). 
contemporaneidade -, o acontecimento está presente em toda atividade" (VEIGA-NETO, 2011, p. 41-42).

Para Veiga-Neto (2011), a reorganização do trabalho na modernidade líquida ocorre com base no modelo do trabalho imaterial, bem como tem apresentado mudanças também na reorganização da forma de controlar a produtividade do trabalhador. Assim, nesse tipo de trabalho “a comunicação não é apenas admissível, mas também necessária. O trabalho imaterial tem por pressuposto a cooperação entre cérebros, uma cooperação que já não é uma divisão do trabalho como na fábrica; não é, nem mesmo, organizada pela empresa" (VEIGANETO, 2011, p. 42).

Nessa perspectiva, a cooperação entre cérebros realiza-se de forma voluntária, pois age sobre os desejos, sobre as vontades, faz com que os indivíduos queiram participar e assim se constitui o trabalho em rede. Essas questões, apresentadas pelo referido autor, vão ao encontro do enfoque dado pela referida competência, pois nela é dada ênfase à flexibilidade, à cooperação e ao mesmo tempo ao agir individual, em que o aluno é responsabilizado pelo andamento dos projetos. De acordo com a competência, o bom andamento de um projeto em grupo é consequência do envolvimento e responsabilidade de cada um com ele, lógica que caracteriza o trabalho em rede.

$\mathrm{Na}$ competência número 7 , é possível perceber que a ênfase também é dada ao trabalho realizado com os pares de forma cooperativa, no que tange ao trabalho e planejamento coletivo, que vai ao encontro das problematizações em torno da competência número 6, que alude o agir de forma cooperativa:

Interagir com seus pares de forma cooperativa, trabalhando coletivamente no planejamento e desenvolvimento de pesquisas para responder a questionamentos e na busca de soluções para problemas, de modo a identificar aspectos consensuais ou não na discussão de uma determinada questão, respeitando o modo de pensar dos colegas e aprendendo com eles. (BRASIL, 2017, p. 223, grifo nosso).

O enfoque dado a ambas as competências tendem à racionalidade neoliberal, em que:

[...] a educação ocupa um lugar absolutamente relevante. Afinal, são justamente as políticas e as práticas educacionais, através principalmente da maquinaria escolar, que engendram as condições de possibilidades para o sucesso do neoliberalismo, na medida em que inventam e colocam em circulação novos dispositivos de circulação, de modo a moldar novas posições de sujeito ou, se quisermos, moldar os novos ambientes sociais de modo a construir novas subjetividades (que adjetivamos de neoliberais). Nesse caso, mais do que criar, reforçar ou reproduzir supostas ideologias, a 
Educação cria condições de que resulta a fabricação de determinadas subjetividades. (VEIGA-NETO, 2013, p. 9-10).

Veiga-Neto (2013), apoiado em Lazzarato, explica que são nos cenários sociais, culturais e educacionais que se fabricam sujeitos neoliberais, ou seja, sujeitos flexíveis, performáticos, empreendedores, autorresponsáveis, aparentemente livres e sempre endividados. E essas características podem também ser observadas nas competências número 6 e 7, que aludem para a formação de um sujeito que saiba agir com autonomia, responsabilidade, flexibilidade e que interajam com seus pares de forma cooperativa.

Nessa mesma linha de pensamento, a competência número 8 apresenta que o aluno deve ser capaz de: "Sentir-se seguro da própria capacidade de construir e aplicar conhecimentos matemáticos, desenvolvendo a autoestima e a perseverança na busca de soluções” (BRASIL, 2017, p. 223, grifo nosso). Logo, são apresentados modos de como o sujeito deve portar-se no componente curricular de Matemática, pois de acordo com ela o aluno deve sentir-se seguro da sua capacidade em construir e aplicar conhecimentos referentes ao componente curricular. É dada ênfase à autoestima e à perseverança do aluno ao buscar soluções. A resolução de problemas já estava assinalada nos PCNs, o documento já apresentava a resolução de problemas como um caminho para o ensino da matemática. Ele apresenta que a resolução de problemas não deve se resumir na aplicação de procedimentos adequados para encontrar respostas corretas. Para o documento, o foco não está na resposta, mas sim no processo de resolução de problemas (BRASIL, 1997). Entretanto, de acordo com Knijnik (1996), os exemplos que são dados em relação ao que é "teorizado" pelo documento apresentam-se como contraexemplos, ou seja, o que é dito não é colocado em prática pelo nível de dificuldade que tal teoria abarca, pois são questão tradicionais que não se caracterizam como problemas.

A perseverança e a busca de soluções como competências atribuídas ao aluno de Ensino Fundamental podem estar relacionadas com o que Bauman (2009) menciona em sua entrevista à professora Alba Porchddu. Para ele, a ênfase mutável,

[...] que se desloca da categoria da "educação" para a "aprendizagem", está em harmonia com uma outra tendência, comum entre os empresários contemporâneos: a inclinação a descarregar sobre as costas dos trabalhadores todas as suas responsabilidades, sobretudo os efeitos negativos e, mais geralmente, a responsabilidade do "fracasso crescimento da mudança" (BAUMAN, 2009, p. 678). 
A responsabilidade com relação à aprendizagem é deslocada para o aluno, no momento em que a competência a ser exigida dele solicita que persevere na busca de soluções, pois ele deve encontrar uma forma de solucionar, ou melhor, de aprender. E essa aprendizagem deve ser construída por ele na aplicação dos conhecimentos matemáticos. Assim, a reponsabilidade em relação à aprendizagem está incutida no aluno, ou, em conformidade com Bauman (2009), descarregada sobre ele, lembrando que a competência 6 também faz menção à reponsabilidade, que aparece vinculada tanto à ação individual quanto à ação de forma cooperativa.

Em relação ao conhecimento em sua forma aplicada em prol de buscar solução, é destacado no excerto da competência 8: “aplicar conhecimentos matemáticos, desenvolvendo a autoestima e a perseverança na busca de soluções” (BRASIL, 2017, p. 223, grifo nosso). Já na introdução da BNCC é dada ênfase ao conhecimento como algo a ser utilizado para um dado momento ou situação, não como um fim em si mesmo. E é dado destaque para a aplicação de problemas para a resolução deles, para a formação de sujeitos proativos para identificar dados de uma situação e buscar soluções. Logo, o documento apresenta que essas competências se contrapõem à concepção de conhecimento desinteressado e erudito. Nesse âmbito, não há interesse na dimensão intelectual, mas sim no conhecimento para alguma coisa.

A solução de problemas é novamente citada na competência 9, em que a Matemática é vista como um produto de diferentes culturas:

Reconhecer que a Matemática é uma ciência humana, fruto das necessidades e preocupações de diferentes culturas, em diferentes momentos históricos, e é uma ciência viva, que contribui para solucionar problemas científicos e tecnológicos e para alicerçar descobertas e construções, inclusive com impactos no mundo do trabalho" (BRASIL, 2017, p. 223, grifo nosso).

No entanto, podemos fazer a seguinte pergunta: a matemática proposta pela BNCC e praticada nas escolas é resultado de quais grupos culturais?

Em relação à Matemática presente nos currículos das escolas, Lizcano (2004, p. 126127) expõe que:

[...] pode ser pensada como o desenvolvimento de uma série de formalismos característicos da maneira peculiar que tem certa tribo de origem europeia de entender o mundo. Por serem seus praticantes habitantes de cidades ou burgos, poderíamos chamá-la "tribo burguesa". Esta matemática burguesa, na qual todos nós (ou talvez somente quase todos) fomos socializados, 
reflete um modo muito particular de perceber o espaço e o tempo, de classificar e ordenar o mundo, de conceber o que se considera impossível.

Assim, é exigido como competência que os alunos reconheçam essa Matemática como ciência humana, não sendo considerados outros conhecimentos matemáticos praticados fora da escola. Assim, somente serão considerados conhecimentos matemáticos se estiverem em consonância com os praticados na disciplina de Matemática. "As práticas matemáticas dos outros ficam assim legitimadas - em função de sua maior ou menor parecença com a matemática que aprendemos nas instituições acadêmicas” (LIZCANO, 2004, p. 125).

De acordo com essas questões abordadas por Lizcano (2004), Veiga-Neto (2003) apresenta questões referentes ao caráter único e unificador da Cultura, ligado a isso está o papel atribuído à educação, recorrendo a Kant, o referido autor apresenta como a educação se tornou uma via para a imposição de um padrão cultural único, “que era ao mesmo tempo branco, machista, de forte conotação judaico-cristã, eurocêntrico e, é claro, de preferência germânico" (VEIGA-NETO, 2003, p. 10). A escola única para todos era uma escola com a ideologia monoculturalista, que estava a serviço do Estado e da Modernidade, pois realizou a tarefa de regular a sociedade tornando-a mais homogênea. Se valendo de Bauman (2009), o autor afirma que a escola foi colocada a serviço da limpeza do mundo. Um mundo mais limpo para que junto com a civilidade se desenvolvesse uma cultura universalista. Sendo assim, as demais produções culturais eram de menor importância, ou melhor, não eram consideradas. Com a redução de tudo e todos ao mesmo, se fixa uma única identidade, rejeitando a diferença.

Porém, como cada pessoa interpreta a realidade e atribui significados de diferentes formas às situações imaginadas, os problemas cotidianos e sociais, e as práticas sociais e culturais, consequentemente suas observações, relações e estratégias também podem ser diferentes. Sabendo disso, como respeitar as individualidades de cada aluno? Um problema cotidiano de uma pessoa que mora no meio rural seria o mesmo de uma pessoa do meio urbano? A matemática dos povos indígenas, dos trabalhadores rurais e dos pedreiros é considerada no contexto escolar? Diante deste mundo com uma pluralidade de culturas, estabelecer normas para ensinar e aprender matemática pode aprisionar as outras possibilidades de raciocínio e saberes?

Além dessas questões, também é atribuída à Matemática a sua importância em relação ao mundo do trabalho. Bauman (2009) - quando questionado sobre como é possível que a educação se reduza a ser quase exclusivamente “formação para o trabalho" inclusive no nível 
das diretivas europeias - explica que é fácil traçar afinidades entre a abordagem utilizada pela Comissão Europeia e as intenções e demandas declaradas por autores que escrevem em prol das empresas. Esses autores seguem, com algumas modificações, o modelo de raciocínio exemplificado por um compêndio popular e influente no pensamento empresarial, segundo o qual

[...] o objetivo da educação é o de "desenvolver trabalhadores, ou seja, aumentar sua cota atual de trabalho e prepará-los para as tarefas que poderão desenvolver no futuro". Esse desenvolvimento deve sempre ser determinado pela "individualização das competências necessárias e pela gestão ativa do aprendizado do trabalhador para um futuro a longo prazo, em relação com estratégias empresarias explícitas" (BAUMAN, 2009, p. 677).

Essas questões podem ser observadas também na introdução da BNCC, onde é dado destaque à importância de "comunicar-se, ser criativo, analítico-crítico, participativo, produtivo e responsável" (BRASIL, 2017, p. 17) e que isso requer mais do que o acúmulo de informações. São esses os requisitos que o novo cenário mundial requer, ou seja, é esse o tipo de sujeito que interessa à sociedade contemporânea. Velhos temas, novos problemas, - indo ao encontro do título dessa seção - podemos pensar na reatualização das competências em nossos currículos escolares, em prol de uma ordem mundial.

Seguindo a discussão das Competências específicas de matemática para o Ensino Fundamental, na próxima seção, temos por objetivo aprofundar as questões referentes à regulação do conhecimento matemático e suas implicações no currículo escolar.

\section{A regulação do conhecimento matemático no currículo escolar}

As Competências específicas de matemática para o Ensino Fundamental da BNCC, analisadas neste estudo, podem ser vistas como ferramentas do discurso pedagógico contemporâneo para disciplinar corpos, como demonstrado nos excertos a seguir: características como agir de forma individual ou de forma cooperativa com autonomia, responsabilidade e flexibilidade para o desenvolvimento elou discussão de projetos são consideradas importantes para a aprendizagem da matemática (competência número 6); é ressaltado que o aluno deve aprender a trabalhar em coletivo para o planejamento $e$ desenvolvimento de pesquisas (competência número 7); e é destacado que o aluno deve ser seguro e possuir autoestima na busca por soluções matemáticas (competência número 8). 
Os ditames elucidados nas competências produzem um modo de ser aluno, uma forma de portar-se e de manejar o conhecimento, bem como nos apresenta quais conhecimentos são importantes e como devemos lidar com eles. Nessa perspectiva analítica, analisamos o movimento moderno de disciplinarização, que, segundo Popkewitz (2001), organiza o conhecimento conforme regras, trazendo a impressão de ordem e hierarquia, mesmo que a situação socioeconômica seja de incerteza.

No sistema "sócio-acadêmico" de relações que os professores constroem para segmentar o conhecimento para seus alunos, os discursos curriculares estabelecem razão e direção para o trabalho do professor quando a esperada aceitação da educação por parte dos alunos não está presente. [...] Essa instrução organiza o conhecimento escolar e, através de sua aplicação, classifica e organiza os alunos segundo critérios "escolares" (POPKEWITZ, 2001, p. 121).

Essa organização está implicada nos documentos que regem as instituições de ensino que, por sua vez, regulam os currículos delas. E essa regulação está implicada em um âmbito maior, pois é produzida por questões econômicas globais. Assim há uma regulação dos comportamentos, como também dos saberes, como demonstrado na competência número 2 , em que é dado destaque a: Estabelecer relações entre conceitos e procedimentos dos diferentes campos da Matemática (Aritmética, Álgebra, Geometria, Estatística e Probabilidade) e de outras áreas do conhecimento e comunicá-las por meio de representações adequadas (BRASIL, 2017, p. 223, grifo nosso).

Para Foucault (2002), o poder disciplinar não se caracteriza como opressor, mas sim como produtor de saberes, que instituem o que é tomado como verdade. Nessa perspectiva, "a verdade não existe fora do poder ou sem poder [...]. A verdade é deste mundo; ela é produzida nele graças a múltiplas coerções e nele produz efeitos regulamentos de poder" (FOUCAULT, 1979, p. 12). Em cada época e espaço há condições de possibilidade para a produção de determinadas verdades, ou seja, cada sociedade tem o seu próprio regime de verdade. Com base nessas questões teóricas, a BNCC apresenta-se como um documento produzido e produtor de verdades que reatualizam discursos que já circulavam em documentos anteriores, citados nesse estudo (Constituição Federal, LDB, PCNs e DCNs).

Knijnik (2016) chama atenção para a atual configuração do mundo globalizado, a vigência da centralidade da ciência na cultura ocidental. E isso pode ser verificado nos discursos que compõem a BNCC, em especial nas competências elencadas para a disciplina de Matemática. "É sabido que a matemática está centralmente implicada nos processos 
tecnocientíficos da atualidade, mesmo que essa implicação ganhe nuances distintas, em função do ramo da matemática que esteja em jogo" (KNIJNIK, 2016, p. 4-5). Para o capitalismo do século XXI não basta apenas gerar conhecimentos científicos, pois o principal objetivo é capacidade de inovação. Nessa perspectiva, o valor do conhecimento está na sua eficácia que é medida por parâmetros estabelecidos Banco Mundial interligado à Organização de Cooperação e de Desenvolvimento Econômico (OCDE), que são os que organizam as leis do mercado multinacional (KNIJNIK, 2016). Como já citado na seção anterior, as competências elencadas pela BNCC estão em consonância com as questões do PISA que, por sua vez, são coordenadas pela OCDE.

Suspeitamos que nossos currículos escolares estão submetidos aos ditames da OCDE, que são produzidos pelas novas configurações do capitalismo na contemporaneidade. E essas configurações se devem aos processos de globalização contemporâneos - que foram nomeados por Hardt e Negri (2001) como Império -, que emergem com o fim dos regimes coloniais ocorrido nas últimas décadas e posteriormente com a derrubada das barreiras soviéticas ao mercado do capitalismo mundial. "Juntamente com o mercado global e com circuitos globais de produção, surgiu uma ordem global, uma nova lógica e estrutura de comando - em resumo, uma nova forma de supremacia" (HARDT; NEGRI, 2001, p. 11). O império, de forma política, tem governado o mundo.

E é nesse cenário que estão implicadas as reformas educacionais. "Estamos também envolvidos com processos educativos daqueles que seguem estudando, sempre estudando, para se preparar para "o futuro" (KNIJNIK, 2016, p. 5). Logo, nunca estamos formados, sempre estamos em busca de formação, nossos conhecimentos perdem validade e precisam constantemente ser atualizados. E isso pode ser conferido nas competências aqui analisadas, como nos excertos a seguir: aplicações práticas (competência 1); práticas sociais e culturais, comunicar informações (competência 3); aspecto-prático utilitário (competência 4); utilizar processos e ferramentas matemáticas (competência 5); aplicar conhecimentos (competência 8); contribuir para solucionar problemas científicos e tecnológicos (competência 9).

Os excertos acima apontam para o tipo de conhecimento que se quer e que se apresenta como produtivo no contexto da nova ordem mundial. A aplicação e a solução de problemas são apontadas como competências a serem desenvolvidas na Educação Básica e efetivadas pelo currículo escolar.

É por tudo isso que se pode dizer que o currículo é um artefato que foi engendrado tanto "a serviço" da ordem e da representação quanto "a 
serviço" das novas lógicas espaciais e temporais que se estabeleceram nos limiares da Modernidade. Nota-se que a própria palavra latina curriculum implica uma ação - necessariamente temporal - que se desenvolve num espaço. (VEIGA-NETO, 2002, p. 171-172, grifo do autor).

“A educação escolar se constitui permeada por normas e diretrizes através das distinções aplicadas" (POPKEWITZ, 2001, p. 106) como na BNCC, cujas competências ditam como a matemática deve ser trabalhada na escola. Assim, a escola constitui sujeitos de determinadas formas, em diferentes lugares e épocas, ensinando quais qualidades consideradas "normais" elas devem "possuir" e quais comportamentos são considerados “adequados” para a época (POPKEWITZ, 2001).

Ao olhar para os excertos da BNCC, percebe-se a matemática como uma ferramenta para aplicação de saberes, bem como para a resolução de problemas, ou seja, seria por meio dela que os alunos acessariam outros tipos de conhecimento. Entretanto, a matemática escolar é um recorte da matemática produzida na Europa em um determinado espaço e tempo, logo há uma imposição da forma com que matematizamos. "Como sabemos, a matemática é considerada uma área interessada com o desenvolvimento da razão, da padronização e das práticas de regulação, de modos específicos de raciocinar que conduzam a generalizações" (KNIJNIK, 2016, p. 7). Como uma área do conhecimento interessada em conduzir nossos modos de pensar e raciocinar, as Competências específicas de matemática para o Ensino Fundamental apresentam formas como conceber a matemática e como utilizá-la com o objetivo de atender os parâmetros do Pisa, ou seja, da OCDE, sendo essa matemática mencionada no documento a matemática escolar.

\section{Questões para finalizar ...}

Ao longo deste trabalho foi possível observar nas competências, enumeradas pela BNCC, a atribuição ao aluno da responsabilidade em relação ao seu aprendizado, bem como a dinamização da sua aprendizagem, ou seja, a produção de sujeitos flexíveis e que consigam perseverar na solução de problemas. A Matemática, como componente curricular, é apresentada como um conhecimento a ser aplicado e utilizado pelo aluno nessa autorresponsabilização e flexibilização, pois cabe a ele encontrar formas de utilizá-la. A Matemática também é apresentada como ciência crucial na resolução de problemas, inclusive no que remete ao mundo do trabalho. 
Inferimos que as discussões em torno das Competências específicas de Matemática para o Ensino Fundamental da BNCC apresentam que esse documento está a serviço da nova configuração econômica mundial. $\mathrm{O}$ documento vem a instituir uma forma de matematizar e agir, como sendo importante para os processos de aprendizagem. Com bases nessas questões, nos perguntamos: Como escapar dos ditames impostos pela nova configuração mundial? Como dizer não aos processos de subjetivação impostos pela globalização? Como criar estratégias para dar visibilidade a outros modos de pensar a matemática? Como dar espaço para outras matemáticas? Ou melhor, na nova ordem mundial econômica há espaços para outras matemáticas? Finalizamos a escrita deste estudo com essas questões, as quais abrem outras possibilidades de pesquisa em Educação Matemática no que tange o currículo escolar.

\section{REFERÊNCIAS}

ASSOCIAÇÃO NACIONAL DE PÓS-GRADUAÇÃO E PESQUISA EM EDUCAÇÃO (Brasil). ANPEd e ABdC lamentam a aprovação da BNCC pelo CNE. 2017. Disponível em: <http://www.anped.org.br/news/anped-e-abdc-lamentam-aprovacao-da-bncc-pelo-cne>. Acesso em: 4 jan. 2018.

BAUMAN, Zimunt. Zigmunt Bauman: entrevista sobre a educação. Desafios pedagógicos e modernidade líquida. Cadernos de Pesquisa, v. 39, n. 137, p. 661-684, maio/ago. 2009.

BRASIL. Constituição (1988). Constituição da República Federativa do Brasil. Brasília, DF: Senado Federal, 1988. Disponível em: <https://www.senado.gov.br/atividade/const/con1988/con1988_15.12.2016/art_210_.asp>. Acesso em: 2 jan. 2018.

BRASIL. Lei $\mathrm{n}^{\circ}$ 9.394, de 20 de dezembro de 1996. Estabelece as diretrizes e bases da educação nacional. Diário Oficial da República Federativa do Brasil, DF, 23 dez. 1996. Seção1. Disponível em: <http://www.planalto.gov.br/ccivil_03/Leis/L9394.htm>. Acesso em: 2 jan. 2018.

BRASIL. Ministério da Educação. Base Nacional Comum Curricular: versão final. Brasília: Ministério da Educação, 2017. Disponível em:

<http://basenacionalcomum.mec.gov.br/images/pdf/0_BNCC-Final_Apresentacao.pdf >. Acesso em: 14 ago. 2017.

BRASIL. Ministério da Educação. Conselho Nacional de Educação. Câmara de Educação Básica. Resolução n ${ }^{\circ}$, de 13 de julho de 2010. Define Diretrizes Curriculares Nacionais Gerais para a Educação Básica. Diário Oficial da União, DF, 14 jul. 2010. Seção1. p. 824.

BRASIL. Ministério da Educação. Planejando a próxima década: conhecendo as 20 metas do Plano Nacional de Educação. Brasília: MEC, 2014. Disponível em:

<http://pne.mec.gov.br/images/pdf/pne_conhecendo_20_metas.pdf>. Acesso em: 2 jan. 2018. 
BRASIL. Ministério da Educação. Secretaria de Educação Fundamental. Parâmetros Curriculares Nacionais: Matemática ( $1^{\circ}$ e $2^{\circ}$ ciclos do ensino fundamental). Brasília: MEC, 1997. v. 3.

COSTA, Marisa Vorraber. Velhos temas, novos problemas: a arte de perguntar em tempos pós-modernos. In: COSTA, Marisa Vorraber; BUJES, Maria Isabel Edelweiss (Org.). Caminhos investigativos III: riscos e possibilidades e pesquisar nas fronteiras. Rio de Janeiro: Dp\&a, 2005. p. 199-214.

FOUCAULT, Michel. A governamentalidade. In: FOUCAULT, Michel. Ditos e escritos IV: estratégias poder-saber. Rio de Janeiro: Forense Universitária, 2003. p. 281-305.

FOUCAULT, Michel. A ordem do discurso: aula inaugural no Collége de France, pronunciada em 2 de dezembro de 1970. Tradução de: Laura Fraga de Almeida Sampaio. 4. ed. São Paulo: Edições Loyola, 1998. 79 p.

FOUCAULT, Michel. Verdade e poder. In: FOUCAULT, Michel. Microfísica do poder. 16. ed. Rio de Janeiro: Graal, 1979. p. 1-14.

FOUCAULT, Michel. Vigiar e punir: história das violências nas prisões. 26. ed. Petrópolis: Vozes, 2002. p. 117-161.

HARDT, Michel; NEGRI, Antonio. Prefácio. In: HARDT, Michel; NEGRI, Antonio. Império. 2. ed. Rio de Janeiro: Record, 2001. p. 11-18.

HOUAISS, Antônio; VILLAR, Mauro de Salles. Dicionário Houaiss da Língua Portuguesa 2009. Rio de Janeiro: Objetiva, 2009. CD-ROM.

KIPPER, Daiane. Práticas matemáticas visuais produzidas por alunos surdos: entre número, letras e sinais. 2015. 145 f. Dissertação (Mestrado em Educação) - Universidade de Santa Cruz do Sul, Santa Cruz do Sul, 2015.

KNIJNIK, Gelsa. Documento 3: parecer de Gelsa Knijnik. Educação \& Realidade, Porto Alegre, v. 21, n. 1, p. 253-259, jan./jun. 1996.

KNIJNIK, Gelsa. Pesquisar em educação matemática na contemporaneidade: perspectivas e desafios. Jornal Internacional de Estudos em Educação Matemática, São Paulo, v. 9, n. 3, p. 1-14, nov. 2016.

LIZCANO, Emmánuel Fernández. As matemáticas da tribo européia: um estudo de caso. In: KNIJNIK, Gelsa; WANDERER, Fernanda; OLIVEIRA, Cláudio José de (Org.).

Etnomatemática, currículo e formação de professores. Santa Cruz do Sul: EDUNISC, 2004. p. 124-138.

ORGANIZAÇÃO DE COOPERAÇÃO E DESENVOLVIMENTO ECONÔMICO. Global Competency for an Inclusive World. Paris: OECD, 2016. Disponível em:

<www.oecd.org/pisa/aboutpisa/Global-competency-for-an-inclusive-world.pdf >. Acesso em: 23 mar. 2017. 
POPKEWITTZ, Thomas S. Lutando em defesa da alma: a política do ensino e a construção do professor. Porto Alegre: Artmed, 2001.

SILVA, Tomaz Tadeu da. Documentos de identidade: uma introdução às teorias do currículo. 3. ed. Belo Horizonte: Autêntica, 2016. 156 p.

SOMER, Luís Henrique. A ordem do discurso escolar. Revista Brasileira de Educação, Rio de Janeiro, v. 12, n. 34, p. 57-67, jan./abr. 2007.

VEIGA-NETO, Alfredo. Cultura, culturas e educação. Revista Brasileira de Educação, Rio de Janeiro, v. 2, n. 23, p. 5-15, 2003.

VEIGA-NETO, Alfredo. De geometrias, currículo e diferenças. Educação \& Sociedade:

Revista de Ciência da Educação, Campinas, v. 23, n. 79, p. 163-186, ago. 2002.

VEIGA-NETO, Alfredo. É preciso ir aos porões. Revista Brasileira de Educação. Rio de Janeiro, v. 17, n. 50, p. 267-282, maio/ago. 2012.

VEIGA-NETO, Alfredo. Estudos de biopolítica e educação na América Latina: avaliação e perspectivas. In: COLÓQUIO LATINOAMERICANO DE BIOPOLÍTICA, 4.; COLÓQUIO INTERNACIONAL DE BIOPOLÍTICA E EDUCAÇÃO, 2., 2013, Bogotá. Anais... Bogotá: [s. n.], 2013.

VEIGA-NETO, Alfredo. Governamentalidades, neoliberalismo e educação. In: BRANCO, Guilherme Castelo; VEIGA-NETO, Alfredo. Foucault: filosofia \& política. Belo Horizonte: Autêntica, 2011. p. 37-52.

\section{SOBRE OS AUTORES:}

\section{Daiane Kipper}

Doutoranda em Educação pela Universidade de Santa Cruz do Sul (UNISC). Membro do Grupo de Pesquisa Identidade e Diferença na Educação. E-mail: daianekipper@hotmail.com iD https://orcid.org/0000-0002-2824-4934

\section{Cláudio José de Oliveira}

Doutor em Educação pela Universidade de Santa Cruz do Sul (UNISC). Membro do Grupo de Pesquisa Identidade e Diferença na Educação. E-mail: coliveir@unisc.br

iD https://orcid.org/0000-0002-9403-0897

\section{Lívia Bittencourt Gomes}

Mestra em Modelagem Matemática pela Universidade de Ijuí (UNIJUÍ). Membro do Grupo de Pesquisa Identidade e Diferença na Educação. E-mail: liviabgomes@yahoo.com.br

(iD) https://orcid.org/0000-0002-0570-9110 